\title{
NOVEL ANTICOAGULANTS BEYOND HEPARIN AND WARFARIN
}

\author{
AKBAR BASHA S $^{1}$, AMBIKA ${ }^{2}$, ABDUL KAREEM S ${ }^{2}$, SUMITHRA M ${ }^{1 *}$
}

Department of Pharmaceutical Chemistry and Analysis, School of Pharmaceutical Sciences, Vels Institute of Science, Technology and Advanced Studies, Chennai, Tamil Nadu, India. Email: sumithrapharmanalysis@gmail.com

Received: 10 October 2018, Revised and Accepted: 11 December 2018

ABSTRACT

Objective: The objective of the study is to know about newer anticoagulant drugs.

Method: The Vitamin K adversaries are the single type of oral anticoagulant in the pharmaceutical, and which is endorsed for long-haul utilize. What is more, the Vitamin K adversaries are exceedingly successful, so it is utilized to avert, and treatment of most thrombotic infections in patients, the noteworthy interpatient and intrapatient are additionally fluctuation in measurement response, and the thin restorative medication record and the more quantities of medication and dietary communications related with these specialists have lead clinicians, patients, and examiners to scan for different operators. The three new orally controlled anticoagulants are apixaban, dabigatran, and rivaroxaban, which are in the late periods of progression and a couple of others they are basically entering (or traveling through), the earlier times of examinations. Those most recent anticoagulant drugs are being contemplated just for the avoidance and furthermore the treatment of venous for the thromboembolism, and the treatment of intense coronary conduit disorders, and furthermore the counteractive action of stroke in patients influenced by atrial fibrillation.

Results: The pharmacological action of the three new orally controlled anticoagulants is apixaban, dabigatran, and rivaroxaban completely reviewed and compared with warfarin.

Conclusion: We are compared the newer anticoagulant with warfarin and discussed about advantages of newer anticoagulants.

Keywords: Anticoagulation, Apixaban, Dabigatran, Novel drugs, Rivaroxaban, Warfarin.

(C) 2018 The Authors. Published by Innovare Academic Sciences Pvt Ltd. This is an open access article under the CC BY license (http://creativecommons. org/licenses/by/4. 0/) DOI: http://dx.doi.org/10.22159/ajpcr.2018.v11s4.31690

\section{REPORT OF ANTICOAGULANT}

In 1960, DM barrit and SC Jordan contend out the principal irregular preliminary demonstrating the viability of medicinal drug treatment within the treatment of blood vessel occlusion. Since at that point, imperative remedial advances have been made in the treatment of profound venous thrombosis and pneumonic embolism. Warfarin has been the medication of choice for the aversion and treatment of blood vessel and venous thrombotic issue for $>40$ years. It is at first marked as a pesticide against rats and mice, is as yet mainstream for this purpose. Ximelagatran was the principal oral direct thrombin inhibitor and had demonstrated viability for the counteractive action of stroke, etc. [1].

\section{Overview}

A blood

A blood foal comprises platelets work into protein, a web-like a set of strands with red platelets, these area unit 2 noteworthy options of the thickening element the platelets and therefore the coagulase system [2].

\section{Platelet}

Modest cell components, made in the bone marrow, that movements in the circulatory system sitting tight for a draining issue to create, when draining happens, substance responses modification the surface of the platelets to create it motivated and finally end up sticky, these initiated platelets begin clinging to the mass of the vein at the location of hurt [3].

\section{Thrombin system}

The coagulation of the Ca particles should be out there for the contains some blood proteins that initiate once exhausting happens, the extracted coagulating proteins participate in an exceedingly course of responses that at long last produce a substance referred to as protein, the protein strands adhere to the uncovered vessel divider, bunching along and shaping a web-like complicated of strands, red platelets progress toward turning into gotten up to hurry within the inflicting the clot [4].

\section{Older anticoagulants}

Warfarin and heparin, low molecular weight heparin.

\section{Newer drugs}

Thrombin inhibitors, Xa inhibitors and Heparinoids.

\section{Anticoagulant use}

Anticoagulant medicine facilitates to keep the development of the damaging activity within the vein. The capability of the blood to cluster those medications is often is constructed in lightweight of the actual fact. The blood thinners they do not, in reality, skinny the blood, these medications will not hack clusters. (Figs. 1 and 2) [5].

\section{Mechanism of action in warfarin}

- Blocks Vitamin K - dependent glutamate carboxylation of precursor factors II, VII, IX, and X

- Vitamin $\mathrm{K}$ = cofactor

- Warfarin blocks the reduction of Vitamin K

- Oral administration.

Warfarin lessens blood cluster arrangement by blocking coagulating factors from framing in the blood. Furthermore, those medication is utilized to counteract strokes, heart assaults, and blood clump development in the lungs, supply routes, and veins. Pregnant ladies ought not to take warfarin. As per Cerner Multan, the medication is known to cause birth abandons, unnatural birth cycles, stillbirths, and fetal bleeding [6]. Practicable symptoms of warfarin are balding, retching, queasiness, stomach torment, swelling, and gas. Look for 


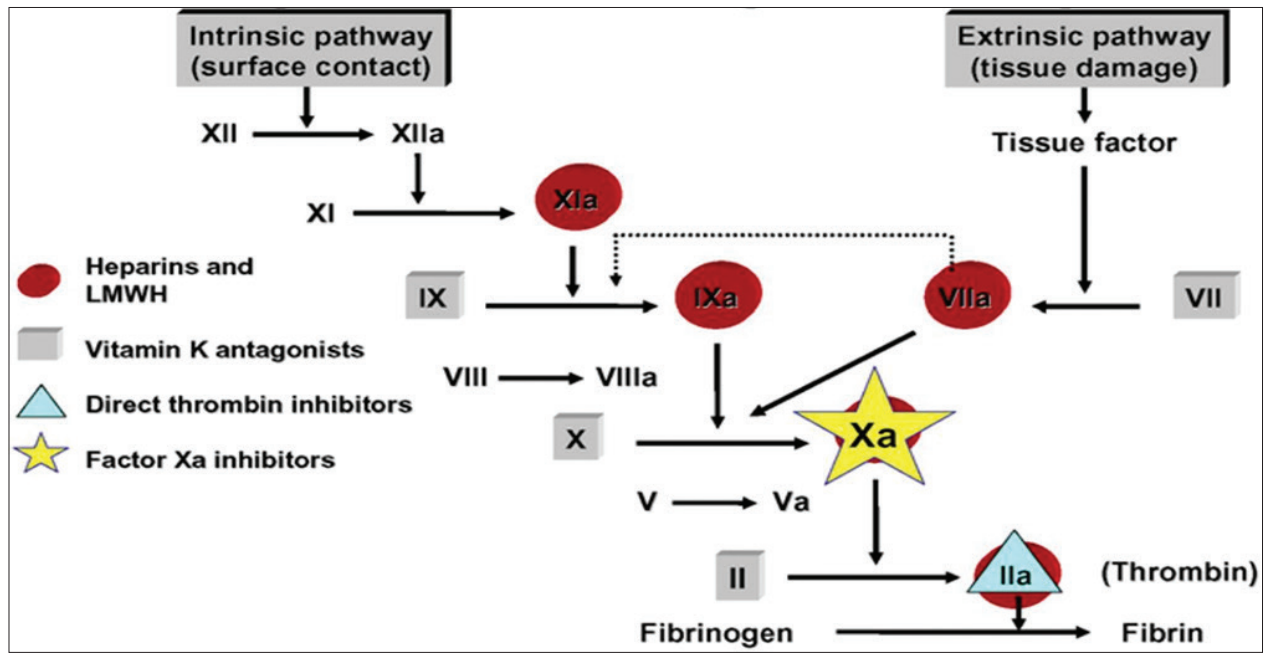

Fig. 1: The targets of anticoagulant drugs

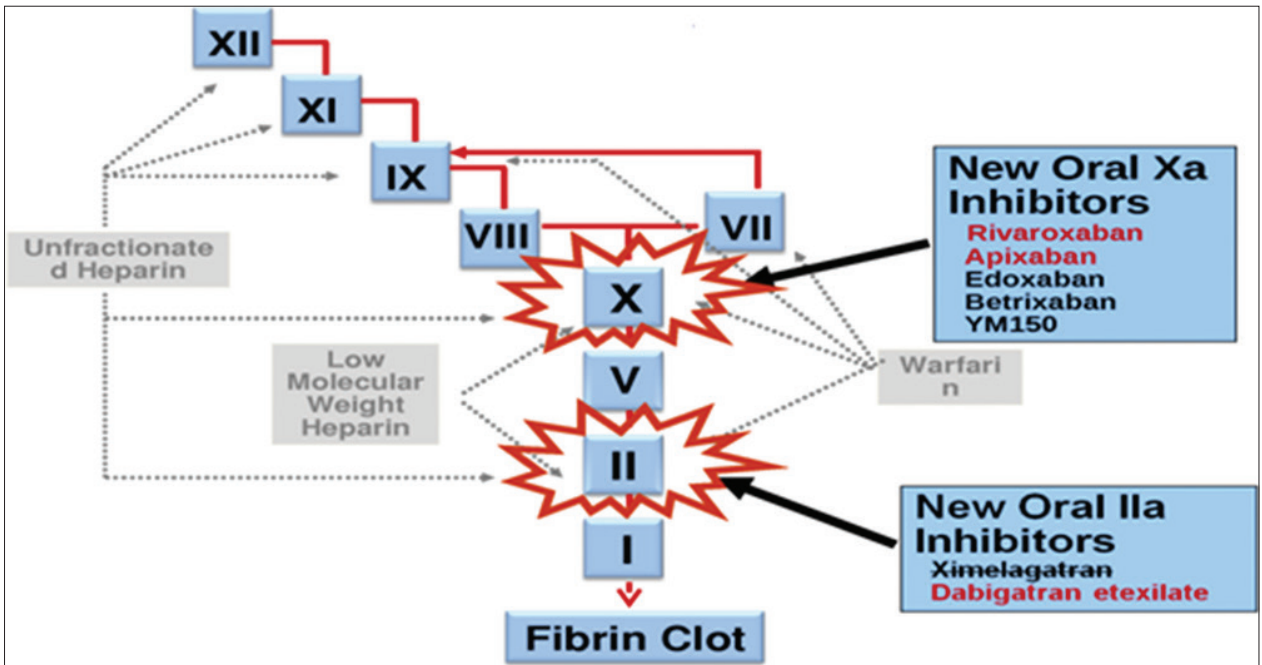

Fig. 2: Mechanism involved in newer anticoagulants

prompt restorative consideration is essential for the draining that would not stop, simple wounding or indications of inside dying, for example, dark, falter stools, or blood in the urine (Table 1) [7].

\section{Review: Anticoagulant medication MOA}

Indirect coagulase inhibitor: $I V$

The indirect coagulase matter is likewise referred to as unfractionated heparin (UFH), thrombin issue Xa XIIa, XIa, and IXa (at the lowest degree) with anticoagulant medication offers the conformational amendment in AT from 1000 to 4000 overlap increasing speed in inactivation, at high fixations and, in addition ties to platelets and anticoagulant medication cofactor II that hinders coagulase. Heparin made from polyose chains of differing lengths. One in every form of a Penta macromolecule succession ties to AT sequence. Every which sent on anticoagulant medication chains it inactivation of thrombin. The anticoagulant medication is to tie each AT and itself. Anticoagulant medication should be lesser than 18 sugar long to try to this for all intents and functions. The all anticoagulant medication atoms area unit lesser than 18 [8].

\section{Limitations of anticoagulant medication and heparin}

Both the anticoagulant medication and, therefore, the Liquaemin have the restricted restorative windows, and therefore the exceptionally extraordinary mensuration reactions that need center perceptive of incomplete lysis time and initiated halfway clotting factor time. Moreover, the medicament heparin also will get attached to another
Table 1: Pharmacodynamic/pharmacokinetic properties of oral anticoagulants

\begin{tabular}{llll}
\hline Drug & $\begin{array}{l}\text { Protein } \\
\text { binding (\%) }\end{array}$ & $\begin{array}{l}\text { Time to peak } \\
\text { concentration }\end{array}$ & Half-life \\
\hline Warfarin (coumarin) & 99 & $4 \mathrm{~h}$ & 1 week \\
Dabigatran (Pradaxa) & 35 & $1-6 \mathrm{~h}$ & $12-17 \mathrm{~h}$ \\
Rivaroxaban (Xarelto) & $92-95$ & $2-4 \mathrm{~h}$ & $5-11.7 \mathrm{~h}$ \\
Apixaban (Eliquis) & 87 & $3-4 \mathrm{~h}$ & $6.8-15.2 \mathrm{~h}$ \\
Edoxaban (Savaysa) & 55 & $1-2 \mathrm{~h}$ & $10-15 \mathrm{~h}$ \\
\hline
\end{tabular}

*Mean values

plasma proteins by creating the bioavailability of the variable, and moreover, the anticoagulant medication has numerous nourishment, sedate interactions. Liquaemin does not inactivate coagulase guaranteed to protein or Xa guaranteed to the platelets [9].

Low relative molecular mass heparins

The atomic mass of heparin $(15,000)$,low sub-atomic weight heparin (4000-5000) and low mass polysaccharide inactivate the Xa but have less impact on coagulase (a few particles not sufficiently long). The proportion against Xa to hostile to coagulase act vitamin of 3:1, It do not extend partial thromboplastin time except if indefinite quantity high [10]. 


\section{WARFARIN IN PATIENTS}

Warfarin is underused in patients United Nations agency need it for the foremost half, and simply $47^{\text {th }}$ of patients are taking Coumadin, this is often as a result of hemorrhagic contraindications, and also the convenience problems as a result of the necessity for visit checking, issue keep up ideal medical care [11]. Warfarin represses the viable integration of naturally dynamic styles of the aliment k-subordinate thickening elements (ii), (vii), (ix), and (x), and conjointly the executive parts macromolecule (c), macromolecule (s), and macromolecule (z) [12].

\section{Direct coagulase inhibitors}

Most square measure peptidomimetic compounds mimic the coagulation factor grouping that cooperates with the coagulase dynamic website, peptidomimetic: An exacerbate that impersonates official and organic antivitamin of the regular amide [13].

\section{Argatroban (novastan)}

Argatroban applies its medicament impacts by preventive the thrombin-impetus or the instigated responses, which includes protein development, effort of natural action factors, as an example, V, VIII, and XIII, supermolecule C, and protoplasm total. Argatroban could be a terribly specific coagulase with the repressive steady (Ki) of $0.04 \mu \mathrm{M}$ [14].

\section{Dabigatran}

Dabigatran is the immediate thrombin inhibitor, and it likewise works by straightforwardly acting the inhibitor of both the free and fibrinbound thrombin. Dabigatran is utilized to avert strokes in those with atrial fibrillation not caused by heart valve issues and in addition profound vein thrombosis and aspiratory embolism. Dabigatran is likewise viewed as a reversible anticoagulant medication. Moreover, it is created by Boehringer Ingelheim; it is a prodrug, dabigatran is a little atom that reversibly represses both free and cluster bound thrombin any authoritative to Exosite 1 as well as the dynamic site of thrombin [15].

\section{Ximelagatran (Exanta)}

In a new class of direct thrombin inhibitors, ximelagatran is the primary oral anticoagulant operator, and it is quickly retained and bioconverted to the dynamic moiety, melagatran, which represses the liquid stage and cluster bound thrombin with comparative high potency. Moreover, it's administered orally, binds reversibly to the active sites, also aprod rug for medicament melagatran [16].

\section{Lepirudin}

Lepirudin is used to isolate the coagulation and abatements thrombocytopenia. It binds to thrombin and maintains a strategic distance from thrombus or group advancement. Lepirudin requires no cofactor for its anticoagulant action. Lepirudin is a recombinant sort of hirudin, an endogenous anticoagulant found in therapeutic leeches [17]. The deterrent of thrombin keeps the blood thickening cascade. It is an extremely solid, specific, and essentially irreversible inhibitor of thrombin and cluster security thrombin. Moreover, half-life of the lepirudin is around $1.3 \mathrm{~h}$ and prompts lethality if there ought to emerge an event of overdosing, and peril of depleting increases [18]

\section{Lab test}

- Thrombin clotting time.

- Seems logical, but is overly sensitive to these drugs and does not provide useful clinical info

- Activated clotting time.

- Ecarin clotting time.

Venom from snake echiscarinatus which converts prothrombin to a meizothrombin that is sensitive to thrombin inhibitors [19].

\section{Factor (Xa) inhibitors}

Fondaparinux (Arixtra)

Fondaparinux is a synthetic pentasaccharide factor Xa inhibitor.
Synthetic polysaccharide

The medication is the one of a kind Penta saccharide grouping that UFH and low sub-atomic weight heparin is use to tie to AT reacts with solid proclivity to AT (reversible) $\rightarrow$ induces conformational change in AT $\rightarrow$ increased capacity to inactivate Xa. Too short to inactivate thrombin (much like low atomic weight heparin) require $>18$ saccharide units to inactivate thrombin. The synthetic polysaccharide does not cooperate with plasma proteins, platelets, or platelet factor IV = helpful in Heparininduced thrombocytopenia (in spite of the fact that not yet formally affirmed) FDA endorsed in 2001-2004/5 endorsement: Venous thromboembolism treatment if managed with warfarin, Anticoagulation in stomach medical procedure.

\section{Drug monitoring}

The half-life of the fondaparinux was found to be $17 \mathrm{~h}$, at assay of antifactor Xa [20].

\section{Idraparinux}

Idraparinux sodium is the novel long-acting manufactured exceptionally intense engineered and particular backhanded inhibitor of coagulation factor Xa, injectable subcutaneously [21]

\section{Rivaroxaban}

Rivaroxaban is a first oral anticoagulant which is known as immediate Xa factor inhibitor. Dissimilar to warfarin, routine lab checking is not essential for this rivaroxaban. Anyway there is no counteractant accessible in case of a noteworthy drain, Rivaroxaban intensely restrains free, and cluster bound factor Xa. Factor Xa enacts the prothrombin (factor II) to thrombin (factor IIa). Rivaroxaban is an anticoagulant which ties straightforwardly to factor Xa. From there on, it adequately obstructs the enhancement of the coagulation course and by keeping the arrangement of thrombus. Rivaroxaban is a unique anticoagulant for a few reasons. For example, it does not include antithrombin III (ATIII) to apply its anticoagulant effects. It is produced by bayer, and it is an orally accessible little atom, dynamic site coordinated factor ( $\mathrm{xa}$ ) inhibitor, and there are no critical connections between foods, antacids, digoxin, ibuprofen, and naproxen [22].

\section{Apixaban}

Apixaban drugs are administered orally, coordinate, and exceedingly the factor of Xa (FXa) for the avoidance and the treatment of thromboembolic. The drug apixaban acts by specifically hindering it in a reversible way, free and clump bound factor Xa to repress coagulation. Apixaban acts by restraining the coagulation, and in this way keeps the advancement of blood clusters. The apixaban draws out thickening tests such as prothrombin time (PT), initiated fractional thromboplastin time (aPTT). Changes saw in these thickening tests at the normal restorative measurements, notwithstanding, are little, subject to a high level of changeability, and not helpful in checking the anticoagulation impact of apixaban. The Rotachrom Heparin chromogenic test is not prescribed for evaluating the anticoagulant impact of apixaban [23]

\section{BENEFITS OF NEWER ANTICOAGULANTS [24]}

- The novel drug anticoagulants are mostly non-Vitamin (k) antagonist

- They are orally administered with safe and effective precautions

- No routine checkup (blood tests) are needed

- The half-life of the drugs are improved

- Lesser the risk of hemorrhage, which is a common adverse effect in anticoagulant medicaments.

\section{Side effects and risks in anticoagulant drugs}

- Increased bruising

- Red or pink colored urine

- Purple appendage [25]

\section{THE FUTURE FOR ANTICOAGULANTS}

Confinements of anticoagulant have inspired an unprecedented enthusiasm for the advancement of novel anticoagulants which are administered orally and intended for use to conceivably succeed anticoagulant [26]. The define of specific inhibitors against atomic 
focuses thereon assume a major half within the activity course are being developed. Sub-atomic targets Arfactor (iia) (thrombin) and factor (Xa). The 2 hopeful mixes, one direct coagulase matters (dabigatran etexilate) and one direct issue (Xa) inhibitor (rivaroxaban), factor (Xa) is associate degree tempting focus for the define of point oral associate degree anticoagulants because of the novel half issue (Xa) plays within the activity course as an association between the outward and inherent pathways. The issue (Xa) likewise controls coagulase age through official to factor (Va) trailed by initiation of clotting factor to coagulase. It's guessed that anticoagulants that specialize in issue (Xa) are also additional powerful than those that specialize in activity factors found drop within the course, for instance, thrombin. This concept has largely incontestible once the most circuitous factor (Xa) matter, fondaparinux, got FDA endorsement for the compensative action and treatment of VTE.

\section{CONCLUSION}

Novel oral anticoagulants area unit in any event as in giving security from occlusion as their condition-particular comparator, new oral anticoagulant area unit nowadays additional pricey than Coumadin. Anticoagulants area unit medication that hinders blood clumps from framing within the veins and provide routes of the body. There utilizes for these medications that incorporate the treatment or compensatory action of:

- Deep vein occlusion

- Blood cluster within the respiratory organ (pneumonic embolism)

- Stroke, heart assault.

\section{ACKNOWLEDGMENTS}

The authors are thankful to the Department of Pharmaceutical Chemistry and Analysis, School of Pharmaceutical Science, Vels Institute of Science Technology and Advanced Studies (VISTAS) Chennai, India, for providing technical support and facilities to carry out the research work.

\section{AUTHORS' CONTRIBUTION}

Conceived and designed the topic and compile the collected data: Wrote the first draft of the manuscript: M. Sumithra. Contributed to the writing of the manuscript: Akbar Basha. S, Ambika, and Abdul Kareem. S. Agree with manuscript results and conclusions and jointly developed the structure and arguments for the paper. Made critical revisions and approved final version: All authors reviewed and approved of the final manuscript.

\section{CONFLICTS OF INTEREST}

There are no conflicts of interest.

\section{REFERENCES}

1. Goodman LS, Gilmans AS. Goodman and Gilmans the Pharmacological Basis of the Therapeutics. 11 $1^{\text {th }}$ ed. New York: McGraw Hill; 1941. p. 937.

2. Medscape.com. Available from: https://www.emedicine.medscape. com/article/1926110-overview. [Last accessed on 2018 Jan 18].

3. Ruff CT, Giugliano RP, Braunwald E, Hoffman EB, Deenadayalu N,
Ezekowitz MD, et al. Comparison of the efficacy and safety of new oral anticoagulants with warfarin in patients with atrial fibrillation: A metaanalysis of randomised trials. Lancet 2014;383:955-62.

4. Lawrence LK. New Anticoagulants. Available from: https://www. uptodate.com/contents/direct-oral-anticoagulants-and-parenteraldirect-thrombin-inhibitors-dosing-and-adverse-effects. [Last accessed on 2012 Nov 08 ].

5. Agnelli G. Venous thromboembolism and cancer: A two way clinical association. Thromb Haemost 1997;78:117-20.

6. Bauer KA. Fondaparinux: Basic properties and efficacy and safety in venous thromboembolism prophylaxis. Am J Orthop 2002;31:4-10.

7. Davidson B. Preparing for the new anticoagulants. J Thromb Thrombolysis 2003;16:49-54.

8. Barritt DW, Jordan SC. Anticoagulant drugs in the treatment of pulmonary embolism: A controlled trial. Lancet 1960;1:1309-12.

9. Walenga JM, Hoppensteadt DA. Monitoring the new antithrombotic drugs. Semin Thromb Hemost 2004;30:683-95.

10. Plovanich M, Mostaghimi A. Novel oral anticoagulants: What dermatologists need to know. J Am Acad Dermatol 2015;72:535-40.

11. Waugh A, Grant A, Waugh A. Ross and Wilson, Anatomy and Physiology in Health and Illness. $12^{\text {th }}$ ed. United Kingdom: Elsevier e-Book Publication; 2018. p. 61.

12. Dager WE, Gulseth MP. Anticoagulation Therapy. ???: ???; 2011. AQ7 p. $45-8$.

13. Rose A. Anticoagulantion Management. 1st ed. Switzerland: ADIS Publisher; 2015. p. 53-77.

14. Alquwaizani M, Buckley L, Adams C, Fanikos J. Anticoagulants: A review of the pharmacology, dosing, and complications. Curr Emerg Hosp Med Rep 2013;1:83-97.

15. O'Sullivan EF. Duration of anticoagulant therapy in venous thromboembolism. Med J Aust 1972;2:1104-7.

16. Dundon JM, Trimba R, Bree KJ, Woods CJ, Laughlin RT. Recommendations for perioperative management of patients on existing anticoagulation therapy. JBJS Rev 2015;3:1874474

17. Froom P, Miron E, Barak M. Oral anticoagulants in the elderly. Br J Haematol 2003;120:526-8.

18. Health Line. Available from: https://www.healthline.com/health/ anticoagulant-and-antiplatelet-drugs\#modal-close. [Last accessed on 2018 Jan 20].

19. Einstein Investigators, Bauersachs R, Berkowitz SD, Brenner B, Buller $\mathrm{HR}$, Decousus $\mathrm{H}$, et al. Oral rivaroxaban for symptomatic venous thromboembolism. N Engl J Med 2010;363:2499-510.

20. Held C, Hylek EM, Alexander JH, Hanna M, Lopes RD, Wojdyla DM, et al. Clinical outcomes and management associated with major bleeding in patients with atrial fibrillation treated with Apixaban or warfarin: Insights from the ARISTOTLE trial. Eur Heart J 2015;36:1264-72.

21. Levine MN, Raskob G, Hirsh J. Hemorrhagic complications of longterm anticoagulant therapy. Chest 1986;89:16-25.

22. Available from: http://www.asheducationbook.hematologylibrary.org/ cgi/reprint/2006/1/450.

23. Schutgens RE, van der Heijden JF, Mauser-Bunschoten EP, Mannucci PM. New concepts for anticoagulant therapy in personswith hemophilia. Blood 2016;128:24714.

24. Coon WW, Willis PW III, Symons MJ. Assessment of anticoagulant treatment of venous thromboembolism. Ann Surg 1969;170:559-68.

25. Harter K, Levine M, Henderson SO. Anticoagulation drug therapy: A review. West J Emerg Med 2015;16:11-7.

26. Marder VJ, Stewart D. Towards safer thrombolytic therapy. Semin Hematol 2002;39:206-16. 